\title{
Value Premium and Portfolio Return Regime: Evidence from European Equities
}

\author{
Chikashi Tsuji \\ Faculty of Economics, Chuo University, Tokyo, Japan \\ Email: mail_sec_low@minos.ocn.ne.jp
}

How to cite this paper: Tsuji, C. (2018) Value Premium and Portfolio Return Regime: Evidence from European Equities. Modern Economy, 9, 434-442. https://doi.org/10.4236/me.2018.93028

Received: February 1, 2018

Accepted: March 17, 2018

Published: March 20, 2018

Copyright (C) 2018 by author and Scientific Research Publishing Inc. This work is licensed under the Creative Commons Attribution International License (CC BY 4.0).

http://creativecommons.org/licenses/by/4.0/

\begin{abstract}
This paper examines the profitability of four European higher return stock portfolios and their linkages between the value premium factor return, high-minus-low (HML), developed by Fama and French. Our fundamental analyses and quantitative examinations using Markov switching models derive the following findings. First, in the four higher return stock portfolios in Europe, the smallest and the highest momentum portfolio shows the highest return. Second, the second smallest and the highest book-to-market (BM) portfolio, the second smallest and the highest operating profitability portfolio, and the second smallest and the second lowest investment portfolio for Europe also demonstrate higher excess returns than the overall stock market in Europe. Furthermore, we also clarify that for all the four European stock portfolios, there clearly exist two regimes: one is positively associated with the value premium factor return, HML, and the other is negatively associated with HML. We further reveal that recently, for all the four portfolios, the high value premium factor loading regimes shift to the other regimes that are uncorrelated with HML. This indicates that, in the recent periods, hedging and risk-diversification effects can be recognized in investing value stocks and the four higher return stock portfolios in Europe.
\end{abstract}

\section{Keywords}

Asset Pricing, European Equity Portfolio, Markov Switching Model, Value Premium

\section{Introduction}

Fama and French [1] recently extended their three-factor model, which was suggested by Fama and French [2], to a five-factor model. In their five-factor model, they newly included an operating profitability factor and a corporate in- 
vestment factor to their three-factor model. However, their value premium factor, high-minus-low (HML), is still important to consider asset pricing of various equities and stock portfolios. How does then this value premium factor return have relations with various stock portfolio returns? Further, are there any regime shifts in the linkages between them?

To reveal these points, this study explores the profitability of European stock portfolios and their linkages between the value premium factor return by using Markov regime-switching models (e.g., Hamilton [3]; Filardo [4]). For our investigations, this paper uses European stock portfolios sorted by several fundamentals such as operating profitability, firm size, corporate investment, book-to-market ratios (BM), and momentum. In existing finance and economics literature, for the US, many investigations for factor returns and effectiveness of asset portfolios were conducted; however, not enough research for European stock portfolios has been implemented. Hence, our analyses of European stock portfolio performances and the linkages of these portfolios and the value premium factor return, HML, are very precious. The main findings derived from our empirical examinations in this paper are as follows.

First, in four higher return stock portfolios in Europe, the smallest and the highest momentum portfolio shows the highest return. Second, the second smallest and the highest BM portfolio, the second smallest and the highest operating profitability portfolio, and the second smallest and the second lowest investment portfolio for Europe also demonstrate higher excess returns than the overall stock market in Europe. These suggest the effectiveness of constructing bivariate-sorted stock portfolios in Europe.

Furthermore, we also clarify that for all the four higher return European stock portfolios, there clearly exist two regimes: one is positively associated with HML and the other is negatively associated with HML. We further reveal that recently, the high HML factor loading regimes shift to the other regimes that are uncorrelated with HML. This indicates that, in the recent periods, hedging and risk-diversification effects can be recognized in investing value stocks and the higher return stock portfolios in Europe.

Regarding the rest of this paper, recent related studies are reviewed in Section 2; in Section 3, the data and variables for our study are introduced; and in Section 4 , the methods for our empirical analyses are explained. After these, Section 5 describes our empirical results and Section 6 summarizes this article.

\section{Literature Review}

This section reviews very recent literature employing regime-switching approach briefly. First, using generalized autoregressive conditional heteroscedasticity (GARCH) and Markov switching models, Caporale et al. [5] examined the effects of stock and bond portfolio inflows on the volatilities of exchange rates using the US and seven developing and emerging countries in Asia. They found that in almost all the cases, high (low) exchange rate volatility was linked to 
stock (bond) inflows from the Asian countries to the US.

Using a regime-switching GARCH mixed data sampling (MIDAS) model, Pan et al. [6] examined the relations between the volatility of oil prices and its macroeconomic fundamentals. The in-sample and out-of-sample test results from their analyses showed that macroeconomic fundamentals can supply useful information as to future oil volatility beyond the historical volatility.

Further, Liu [7] generalized the conditional value at risk (CoVaR) approach suggested by Adrian and Brunnermeier [8] to take into account regime-switching between high and normal risk regimes. This study suggested that considering regime changes was effective for capturing not only amplification but also mean-reversion effects of systemic risks. Aristeidis and Elias [9] studied the effects of the Brexit in June 2016 using regime-switching copulas suggested by da Silva Filho et al. [10]. They found that significant effects of financial contagion from the Brexit to many other international countries.

Furthermore, Zhipeng and Shenghong [11] developed a Markov switching GARCH model, and they found that the application of their model for deriving hedge ratios was effective. Moreover, BenSaïda [12] applied regime-switching copula models to US and European bonds. They suggested that the regime-switching copula models better explained the dynamics of data dependence than the single-regime copula approach.

It is noted that European stock portfolio return analysis using regime-switching approach was little seen in previous studies, though Tsuji [13] attempted such analyses for Japanese stock portfolios. Thus, applying regime-switching models, we investigate portfolio returns and value premium factor return in Europe in the following sections.

\section{Data and Variables}

In this section, we document the data and variables for our empirical study. All data are from Kenneth French and this study uses monthly percentage excess returns over risk-free rate related to four bivariate-sorted European stock portfolios. First are the excess returns as to the portfolios sorted by size and BM ratios (hereafter "Size/BM portfolios"). Second are the excess returns as to the portfolios sorted by size and operating profitability (hereafter "Size/OP portfolios").

Third are the excess returns as to the portfolios based on size and (corporate) investment (hereafter "Size/Inv portfolios"), and fourth are those as to the portfolios based on size and 12-month prior to 2-month prior returns (hereafter "Size/Mom portfolios"). In Fama and French [1], the details of these four portfolio constructions are documented. The sample period for our study is from November 1990 to November 2017, and all excess returns are in US dollars. We also use the excess returns of European overall stock market.

From the four bivariate-sorted European stock portfolios, we first select the highest return portfolio. All the four portfolios from Kenneth French include 25 
portfolio returns because all have $5 \times 5=25$ portfolios. Checking the values of average excess returns of the above four kinds of European stock portfolios, in 25 Size/BM portfolios, the second smallest and the highest BM portfolio shows the highest return (hereafter "Size2/BM5"), and in 25 Size/OP portfolios, the second smallest and the highest operating profitability portfolio records the highest return (hereafter "Size2/OP5").

Further, in 25 Size/Inv portfolios, the second smallest and the second lowest investment portfolio records the highest return (hereafter "Size2/Inv2"), and finally, the smallest and the highest momentum portfolio exhibits the highest return in 25 Size/Mom portfolios (hereafter "Size1/Mom5").

Based on the above evidence, we exhibit the descriptive statistics related to the excess returns over risk-free rate for the four European higher return stock portfolios in Table 1. From the mean values in Table 1, in Europe, Size1/Mom5 displays the highest monthly excess return of 1.65 percent and Size2/OP5 displays the second highest monthly excess return of 1.01 percent.

As Table 1 exhibits, as the average monthly excess return for the European overall stock market is 0.55 percent, in addition to Size1/Mom5 and Size2/OP5, Size2/BM5 and Size2/Inv2 show higher monthly excess returns than overall stock market in Europe (The average monthly excess returns for Size2/BM5 and Size2/Inv2 are both 0.81 percent). Table 1 also indicates that all the four monthly excess portfolio returns are negatively skewed and associated with fat-tailed distributions because all the returns show negative skewness and higher kurtosis than three that is the kurtosis value for normal distributions. From Table 1, we also understand that the volatilities of four stock portfolios are slightly higher than that of overall stock market in Europe excluding Size2/Inv2, which is the lowest-volatility portfolio in all five series in Table 1 .

\section{Methods}

This section explains our methodology. For our examinations, this paper uses

Table 1. Summary statistics of excess stock returns: From November 1990 to November 2017.

\begin{tabular}{cccccc}
\hline & Overall market & Size2/BM5 & Size2/OP5 & Size2/Inv2 & Size1/Mom5 \\
\hline Mean & 0.5547 & 0.8145 & 1.0146 & 0.8081 & 1.6470 \\
Median & 0.7500 & 0.5700 & 1.0100 & 0.8000 & 1.9300 \\
Max. & 13.6700 & 16.9900 & 20.5300 & 13.8500 & 19.7600 \\
Min. & -22.0200 & -26.5700 & -26.0800 & -23.7200 & -22.5000 \\
SD & 4.8244 & 5.2503 & 5.2412 & 4.7749 & 5.1794 \\
Skewness & -0.5853 & -0.4556 & -0.5766 & -0.6124 & -0.4183 \\
Kurtosis & 4.7620 & 5.5133 & 5.8636 & 5.6506 & 5.0768 \\
\hline
\end{tabular}

Notes. SD denotes the standard deviation value. Max. and Min. denote maximum and minimum values, respectively. 
the following Markov regime-switching model (1). For investigating the profitability of the four European stock portfolios and their relations between the value premium factor, HML, we specify the model to have high and low HML factor loading regimes as follows:

$$
r_{t}=\theta_{m}+h_{m} H M L_{t}+\sigma \omega_{t} .
$$

In model (1), $r_{t}$ indicates the excess return from one of the above-mentioned four European higher return stock portfolios, and $H M L_{t}$ denotes the value premium factor return of Fama and French [2]. Moreover, $\theta_{m}$ and $h_{m}$ denote the regime-dependent constant terms and coefficients of the model, respectively; and $m$ denotes the regimes in our model.

Furthermore, model (1) assumes that the error term, $\omega_{t}$ follows a standard normal distribution, and $\sigma$ in this model is the standard deviation (volatility). Model (1) also assumes that this error term is independent and identically distributed (iid). As documented, our model (1) has two regimes of high and low HML factor loading regimes. Further, all models for the four European excess portfolio returns are estimated by the maximum likelihood method.

\section{Results and Interpretations}

In this section, we explain our empirical results derived from the applications of our model (1). In Table 2, the estimation results of our Markov regime-switching models with high and low HML factor loading regimes are displayed. Moreover, in Figure 1, the Markov switching high and low HML factor loading regime probabilities as to the four higher return European stock portfolios are shown. All models are well estimated as seen in all panels of Table 2 and Figure 1.

First, from Panel A in Table 2, as the model estimates for the HML coefficients indicate, for the Size2/BM5 European portfolio, there are clearly two regimes. That is, one is positively associated with HML factor return and the other has negative relations with HML factor return. From Panel A in Figure 1, it is understood that excluding around 2000 to 2003 and after around 2016, the Size2/BM5 portfolio return is positively associated with HML.

Next, from Panel B in Table 2, as the model estimates for the HML coefficients suggest, for the Size2/OP5 European portfolio, there clearly exist two regimes. Namely, one is positively associated with HML factor return and the other is negatively associated with HML factor. In addition, from Panel B in Figure 1, we understand that excluding around 2000 to 2003 and after around 2016, the Size2/OP5 portfolio return is positively associated with HML.

Third, from Panel C in Table 2, as the model estimates for the HML coefficients indicate, for the Size2/Inv2 European portfolio, there are also clearly two regimes, namely, one is positively associated with HML and the other has negative relations with HML. From Panel C in Figure 1, it is understood that again, excluding around 2000 to 2003 and after around 2016, the Size2/Inv2 portfolio return is positively associated with HML.

Finally, from Panel D in Table 2, as the model estimates for the HML 
Table 2. Results of Markov switching regressions with high and low HML loading regimes.

\begin{tabular}{|c|c|c|c|c|c|}
\hline \multicolumn{3}{|c|}{ Panel A. Size2/BM5 Portfolio } & \multicolumn{3}{|c|}{ Panel B. Size2/OP5 Portfolio } \\
\hline \multicolumn{3}{|c|}{ High HML loading regime } & \multicolumn{3}{|c|}{ High HML loading regime } \\
\hline & Estimates & $p$-value & & Estimates & $p$-value \\
\hline Intercept & $0.6015^{\star \star}$ & 0.0295 & Intercept & $0.9891^{\star * *}$ & 0.0012 \\
\hline HML & $1.8977^{* * *}$ & 0.0000 & HML & $1.4130^{\star * *}$ & 0.0000 \\
\hline \multicolumn{3}{|c|}{ Low HML loading regime } & \multicolumn{3}{|c|}{ Low HML loading regime } \\
\hline & Estimates & $p$-value & & Estimates & $p$-value \\
\hline Intercept & 0.6521 & 0.2708 & Intercept & $1.1690^{* *}$ & 0.0469 \\
\hline HML & -0.0014 & 0.9926 & HML & $-0.7112^{\star * *}$ & 0.0000 \\
\hline $\ln \sigma$ & $1.4235^{* * *}$ & 0.0000 & $\operatorname{Ln} \sigma$ & $1.5047^{* * *}$ & 0.0000 \\
\hline LL & \multicolumn{2}{|c|}{-932.9821} & LL & \multicolumn{2}{|c|}{-959.7233} \\
\hline \multicolumn{3}{|c|}{ Panel C. Size2/Inv2 Portfolio } & \multicolumn{3}{|c|}{ Panel D. Size1/Mom5 Portfolio } \\
\hline \multicolumn{3}{|c|}{ High HML loading regime } & \multicolumn{3}{|c|}{ High HML loading regime } \\
\hline & Estimates & $p$-value & & Estimates & $p$-value \\
\hline Intercept & $0.7191^{\star \star}$ & 0.0179 & Intercept & $1.3288^{\star * \star}$ & 0.0000 \\
\hline HML & $1.4983^{* * *}$ & 0.0000 & HML & $1.1133^{* * *}$ & 0.0000 \\
\hline \multicolumn{3}{|c|}{ Low HML loading regime } & \multicolumn{3}{|c|}{ Low HML loading regime } \\
\hline & Estimates & $p$-value & & Estimates & $p$-value \\
\hline Intercept & 0.6019 & 0.2675 & Intercept & $3.3594^{\star * *}$ & 0.0000 \\
\hline HML & -0.1457 & 0.3341 & HML & $-1.0502^{* * *}$ & 0.0000 \\
\hline $\ln \sigma$ & $1.4026^{* * *}$ & 0.0000 & $\ln \sigma$ & $1.5001^{* * *}$ & 0.0000 \\
\hline LL & \multicolumn{2}{|c|}{-925.5339} & LL & \multicolumn{2}{|c|}{-956.2988} \\
\hline
\end{tabular}

Notes. This table shows the estimation results of the Markov switching models with two regimes for the period from November 1990 to November 2017. LL denotes the log-likelihood value. ${ }^{* * *}$ and ${ }^{* *}$ indicate the statistical significance of the estimates at the $1 \%$ and $5 \%$ levels, respectively.

coefficients suggest, for the Size1/Mom5 European portfolio, again, there are clearly two regimes: one is positively associated with HML and the other is negatively associated with HML. From Panel D in Figure 1, similar with the other three portfolios, excluding around 2000 to 2003 and after around 2016, the Size1/ Mom5 portfolio return is positively associated with HML.

As above, it is emphasized that the empirical results from our two-regime Markov switching models are very clear for all the four European stock portfolios. All the four European higher return stock portfolios examined in this study have positive relations with HML for longer in our analyzing sample period. Hence, all the four European stock portfolio returns mostly evolve with showing some positive correlations with HML. However, as Figure 1 shows, recently, the high HML factor loading regimes shift to the other regimes that are uncorrelated with HML. Thus, in the recent periods, hedging and risk-diversification effects can be recognized in investing value stocks and higher return stock portfolios in 
Panel A. Size2/BM5 Portfolio

High HML loading regime

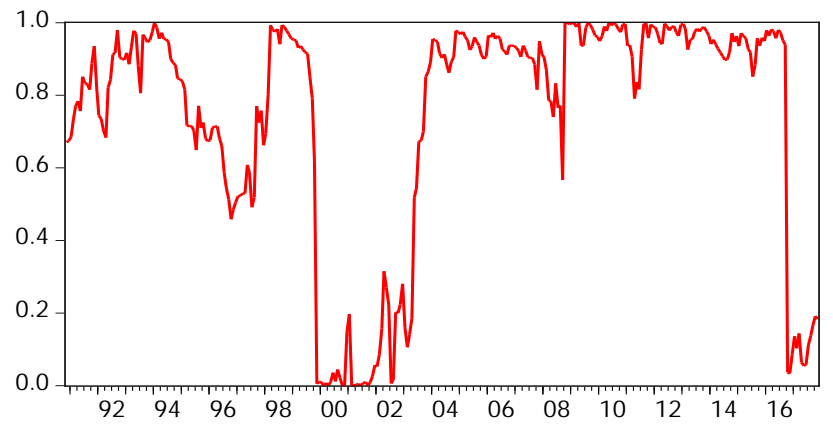

Low HML loading regime

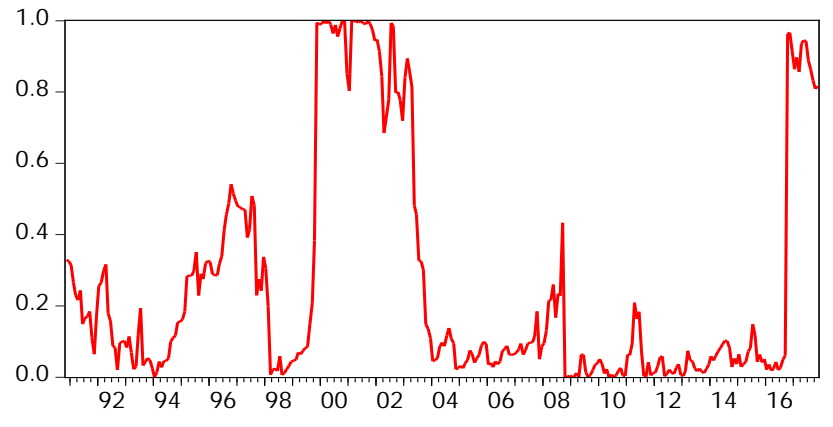

Panel C. Size2/Inv2 Portfolio

High HML loading regime
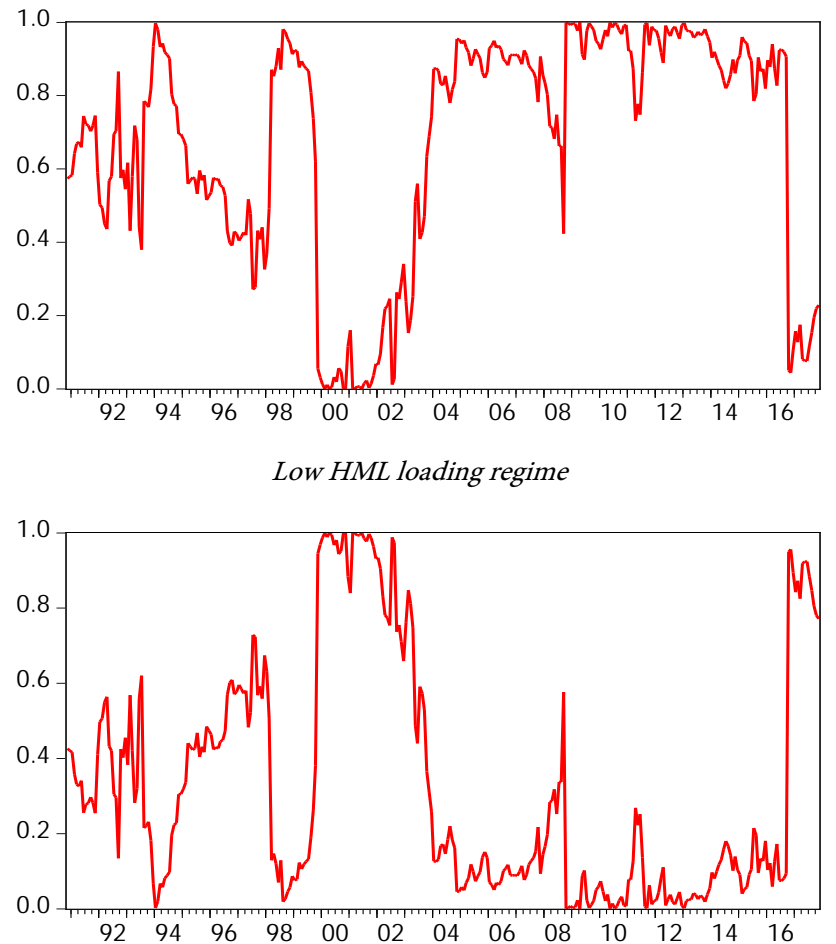

Panel B. Size2/OP5 Portfolio

High HML loading regime
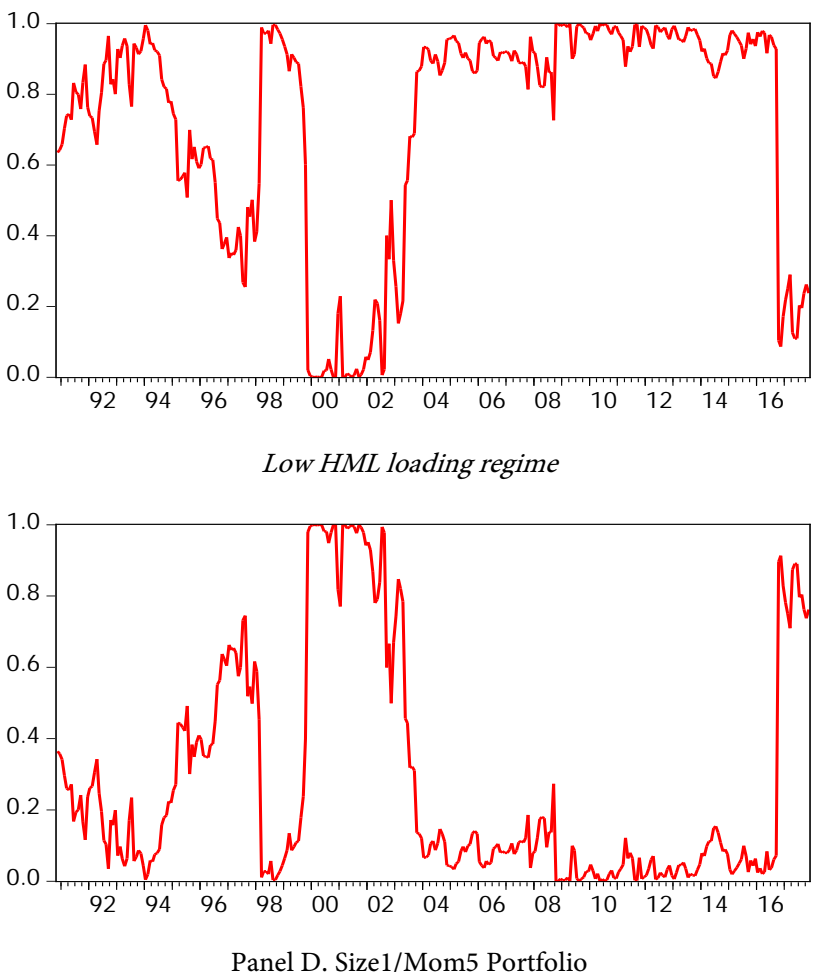

High HML loading regime
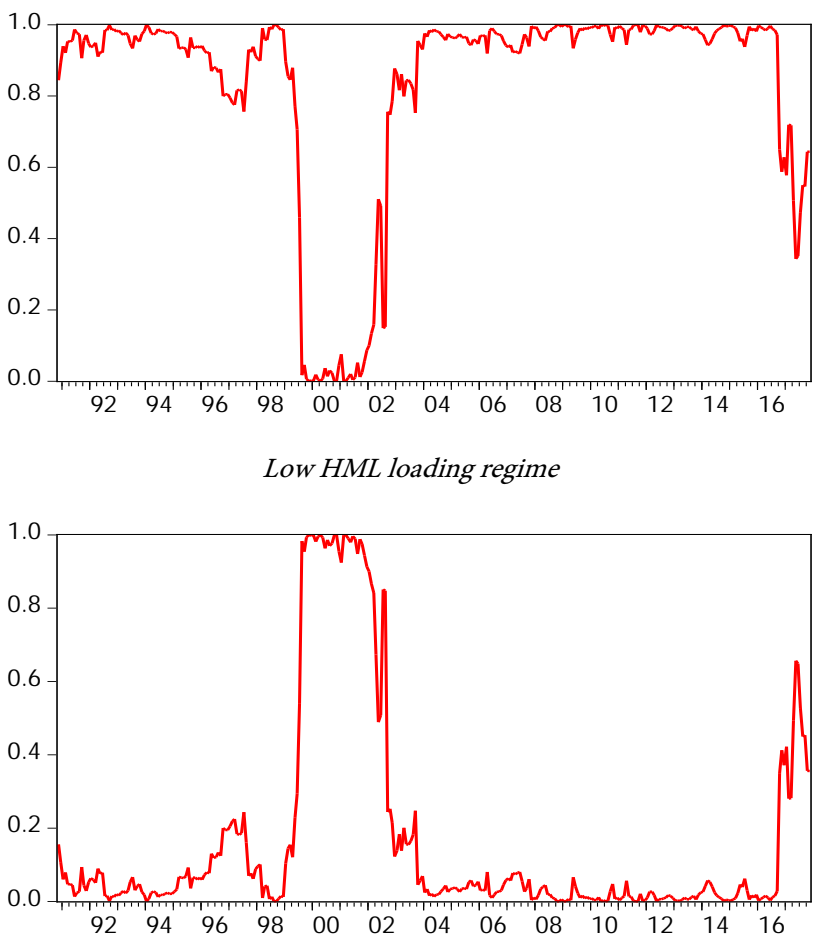

Figure 1. Markov switching regime probabilities for high and low HML loading regimes: For European stock portfolios from November 1990 to November 2017. 
Europe. It is noted that this viewpoint is rather interesting and it shall be important to keep looking at this point in the future as well.

\section{Conclusions}

This paper has investigated the profitability of four European higher return stock portfolios and their relations between value premium factor return of Fama and French [2]. For our sample period from November 1990 to November 2017, the second smallest and the highest BM stock portfolio in Europe, the second smallest and the highest operating profitability stock portfolio for Europe, the second smallest and the second lowest investment stock portfolio for Europe, and the smallest and the highest momentum stock portfolio in Europe recorded higher returns than the overall stock market in Europe. From fundamental analyses and quantitative examinations by applying Markov regime-switching models with high and low value premium factor loading regimes, this study obtained the following interesting evidence.

1) First, in the four kinds of higher return stock portfolios in Europe, the smallest and the highest momentum portfolio showed the highest return. While monthly overall stock market excess return in Europe was 0.55 percent, the smallest and the highest momentum portfolio demonstrated the monthly excess return of 1.65 percent in Europe.

2) Second, the second smallest and the highest BM portfolio, the second smallest and the highest operating profitability portfolio, and the second smallest and the second lowest investment portfolio also yielded higher excess returns than the overall stock market in Europe. These mean the effectiveness of constructing bivariate-sorted stock portfolios in Europe.

3) Furthermore, our analyses using two-regime Markov switching models clarified that for all the four European stock portfolios, there clearly exist two regimes: one was positively associated with the value premium factor return and the other was negatively associated with the value premium factor return. Further, our analyses revealed that recently, the high value premium factor loading regimes shift to the other regimes that are uncorrelated with the factor return. Hence, in the recent periods, hedging and risk-diversification effects can be seen in investing value stocks and higher return stock portfolios in Europe. It is emphasized that this viewpoint is highly important for effective equity investments; and thus, we should keep looking at this point in the future as well.

As demonstrated in this study, employing regime-switching models to examine stock returns is effective and meaningful for deriving new evidence for the fields of investment, asset pricing, and financial risk management. Extended research by applying similar regime-switching approach with different financial data sets should be useful and meaningful, and therefore, it is one of our future works.

\section{Acknowledgements}

The author firstly appreciates this journal for its repeated kind article invitation. 
The author also highly appreciates Jasmyn Chen and Joy Deng for their kind editorial assistance to this article. Further, the author thanks anonymous reviewers for their constructive and supportive comments on this paper. Furthermore, the author also greatly appreciates the Japan Society for the Promotion of Science Grant-in-Aid for Scientific Research and the Chuo University Personal Research Grant for their generous financial assistance to my research. Finally, I deeply thank all the Editors of this journal for their kind attention to my paper.

\section{References}

[1] Fama, E.F. and French, K.R. (2015) A Five-Factor Asset Pricing Model. Journal of Financial Economics, 116, 1-22. https://doi.org/10.1016/j.jfineco.2014.10.010

[2] Fama, E.F. and French, K.R. (1993) Common Risk Factors in the Returns on Stocks and Bonds. Journal of Financial Economics, 33, 3-56. https://doi.org/10.1016/0304-405X(93)90023-5

[3] Hamilton, J.D. (1989) A New Approach to the Economic Analysis of Nonstationary Time Series and the Business Cycle. Econometrica, 57, 357-384. https://doi.org/10.2307/1912559

[4] Filardo, A.J. (1994) Business-Cycle Phases and Their Transitional Dynamics. Journal of Business \& Economic Statistics, 12, 299-308.

[5] Caporale, G.M., Ali, F.M., Spagnolo, F. and Spagnolo, N. (2017) International Portfolio Flows and Exchange Rate Volatility in Emerging Asian Markets. Journal of International Money and Finance, 76, 1-15. https://doi.org/10.1016/j.jimonfin.2017.03.002

[6] Pan, Z., Wang, Y., Wu, C. and Yin, L. (2017) Oil Price Volatility and Macroeconomic Fundamentals: A Regime Switching GARCH-MIDAS Model. Journal of Empirical Finance, 43, 130-142. https://doi.org/10.1016/j.jempfin.2017.06.005

[7] Liu, X. (2017) Measuring Systemic Risk with Regime Switching in Tails. Economic Modelling, 67, 55-72. https://doi.org/10.1016/j.econmod.2016.09.015

[8] Adrian, T. and Brunnermeier, M.K. (2016) CoVaR. American Economic Review, 106, 1705-1741. https://doi.org/10.1257/aer.20120555

[9] Aristeidis, S. and Elias, K. (2018) Empirical Analysis of Market Reactions to the UK's Referendum Results-How Strong Will Brexit Be? Journal of International Financial Markets, Institutions \& Money, 53, 263-286. https://doi.org/10.1016/j.intfin.2017.12.003

[10] da Silva Filho, O.C., Ziegelmann, F.A. and Dueker, M.J. (2012) Modeling Dependence Dynamics through Copulas with Regime Switching. Insurance: Mathematics and Economics, 50, 345-356. https://doi.org/10.1016/j.insmatheco.2012.01.001

[11] Zhipeng, Y. and Shenghong, L. (2018) Hedge Ratio on Markov Regime-Switching Diagonal Bekk-Garch Model. Finance Research Letters, 24, 49-55.

https://doi.org/10.1016/j.frl.2017.06.015

[12] BenSaïda, A. (1994) The Contagion Effect in European Sovereign Debt Markets: A Regime-Switching Vine Copula Approach. International Review of Financial Analysis, In Press.

[13] Tsuji, C. (2012) Positive Return Premia in Japan. Quantitative Finance, 12, 345-367. https://doi.org/10.1080/14697688.2010.541485 